\title{
Introduction to the minisymposium on quality and clinical practice management
}

\author{
Richard E. Heller III ${ }^{1}$ - Lane F. Donnelly ${ }^{2}$
}

Received: 3 January 2017 / Accepted: 15 February 2017 /Published online: 7 June 2017

(C) Springer-Verlag Berlin Heidelberg 2017

We are pleased to present a minisymposium on quality and clinical practice management. Although quality and clinical practice management are separate editorial categories of this journal, we believe it is of benefit to present these topics together because they are inherently complementary and increasingly interrelated. Ensuring the quality of clinical services has always been the focus of those managing clinical operations. This process is becoming increasingly formalized as a result of evolving political and economic forces, as well as a shared desire to improve care.

Articles in this minisymposium cover such important topics as malpractice, quality improvement initiatives, use of information technology to advance departmental goals, and the trend toward 24/7 attending-level coverage. This minisymposium also covers pay-forperformance at the level of the individual radiologist, as well as the trend toward value-based payment at the departmental level, and their relevance to the pediatric radiology sub-specialty. A special guest, Dr. Ezequiel Silva, an interventional radiologist and chair of the American College of Radiology's Commission on Economics, offers his reflections and insights on valuebased payment, which until recently has been a significant topic of discussion primarily among our adultfocused radiology colleagues.

Finally, we would like to thank all of the authors for their work on this project and Pediatric Radiology's editor for the Americas, Dr. Peter Strouse, and editorial assistant Patricia Vario, for shepherding it through to completion.

Compliance with ethical standards

Conflicts of interest None

Richard E. Heller III

richard.heller@radpartners.com

1 Radiology Partners,

2101 El Segundo Blvd., Suite 401, El Segundo,

CA 90245, USA

2 Department of Radiology, Texas Children's Hospital, Houston, TX, USA 